\title{
Anatomia dos órgãos vegetativos de Dieffenbachia picta Schott (Araceae) com ênfase na distribuição de cristais, laticíferos e grãos de amido
}

\author{
Leandro de Santis Ferreira, Fábio Júnio Marsola, Simone de Pádua Teixeira* \\ Departamento de Ciências Farmacêuticas, Faculdade de Ciências Farmacêuticas de Ribeirão Preto, Universidade \\ de São Paulo, Av. do Café, s/no , 14040-903, Ribeirão Preto, SP, Brasil
}

\begin{abstract}
RESUMO: A distribuição dos cristais, laticíferos e grãos de amido foi estudada nos órgãos vegetativos de Dieffenbachia picta Schott (Araceae), conhecida por comigo-ninguém-pode, por tais estruturas serem citadas como responsáveis pela irritação mecânica e química provocada pela planta. A anatomia da folha, do caule aéreo, do rizoma e da raiz foi descrita por meio de seções histológicas coradas com azul de toluidina. A natureza química dos cristais e a presença de lipídios, alcalóides, grãos de amido e proteínas foram verificadas por reagentes diversos. Drusas e ráfides de oxalato de cálcio, associadas a lipídios, alcalóides e proteínas, ocorreram no interior de células presentes no parênquima de todos os órgãos, no colênquima caulinar e nos meristemas da raiz. $\mathrm{O}$ tempo de dissolução dos cristais das folhas jovem e adulta foi semelhante, o do caule foi maior que o da folha e o do rizoma maior que o da raiz. Grãos de amido, associados a proteínas, ocorreram no clorênquima do caule aéreo (forma de bastonetes) e rizoma (formas esférica e bastonete). Laticíferos ocorreram entremeando o colênquima e o parênquima; o látex continha ráfides, alcalóides e lipídios. Maior número de idioblastos cristalíferos e laticíferos foi observado no caule aéreo, sendo este, portanto, o órgão que mais representa perigo.
\end{abstract}

Unitermos: Dieffenbachia picta, comigo ninguém pode, drusa, idioblasto cristalífero, látex, planta tóxica, ráfide.

\begin{abstract}
Anatomy of the vegetative organs from Dieffenbachia picta Schott (Araceae) with an emphasis on crystals, laticifers and starch grains". We studied the distribution of crystals, laticifers and starch grains of the vegetative organs from dumb cane, Dieffenbachia picta Schott (Araceae), known in Brazil as "comigo-ninguém-pode" for such structures are meant to be responsible for mechanical and chemical irritation events carried out by the plant. We described the anatomy of leaves, aerial stems, rhizomes and roots with histological sections dyed in toluidine blue. We checked the chemical nature of crystals and the presence of lipids, alkaloids, starch grains and proteins with various reagents. Druses and calcium oxalate raphides - associated with lipids, alkaloids and proteins - were found in idioblasts spread in the parenchyma of all organs, in the collenchyma of the shoot and in the root meristems. Regarding the dissolution time, it was analogous for crystals in both young and old leaves; it was higher in stems than in leaves and higher in rhizomes than in roots. Starch grains associated with proteins were found in the chlorenchyma of the aerial stem (rod-shaped) and in rhizomes (spherical and rod-shaped). Laticifers were found interspersing parenchyma and collenchyma; raphides, alkaloids and lipids were found in latex. We found a higher number of crystals and laticifers in the aerial stem, and therefore such structure is the most dangerous organ if eaten or swallowed.
\end{abstract}

Keywords: Dieffenbachia picta, dumb cane, crystalliferous idioblast, druse, latex, raphide, toxic plant.

\section{INTRODUÇÃO}

A família Araceae é constituída por cerca de 100 gêneros e 3000 espécies. No Brasil, ocorrem 35 gêneros e cerca de 400 espécies (Souza; Lorenzi, 2005). Seus representantes apresentam distribuição cosmopolita, mas estão melhor representados nas regiões tropical e subtropical, sendo muito comuns em florestas tropicais (Judd et al., 2002). São herbáceos, escandentes ou epífitos, às vezes aquáticos; possuem rizomas ou cormos, ráfides de oxalato de cálcio e, ocasionalmente, látex (Souza;
Lorenzi, 2005). Suas folhas são alternas e, quando jovens, são protegidas por uma grande estípula persistente ou caduca. A inflorescência é uma espádice simples, axilar, de produção sucessiva ou terminal e, neste caso, sendo anual, formada diretamente do rizoma, sempre protegida por uma bráctea, a espata, que comumente é vistosa (Joly, 1991; Souza; Lorenzi, 2005).

Dentre os gêneros ornamentais, destaca-se Dieffenbachia, com 40 espécies (Judd et al., 2002), sendo Dieffenbachia picta Schott bastante conhecida no Brasil pelos nomes populares "aningá-do-pará" ou 
"comigo-ninguém-pode". As principais características desta espécie são as folhas grandes, oblongas, com cerca de 30 a $60 \mathrm{~cm}$ de comprimento, apresentando desenhos coloridos ornamentais em branco; frutos na forma de bagas; látex esbranquiçado; e cristais de oxalato de cálcio em forma de ráfides e drusas (Schutz,1968). D. picta é considerada tóxica (Joly, 1991; Schutz, 1968; Gardner, 1994; Carneiro et al., 1985; Prychid; Rudall, 1999; Tokarnia et al., 2000; Oliveira et al., 2003) e no Hospital das Clínicas de Ribeirão Preto é a principal responsável pelos casos de internação por intoxicação (Oliveira et al., 2003). As intoxicações acometem principalmente crianças e animais domésticos e ocorrem por ingestão ou contato de mucosas, pele e olhos com partes lesionadas da planta. Sua toxicidade é conhecida há muito tempo. Documentos do julgamento do Tribunal de Nurenberg mostram que os nazistas utilizavam o extrato aquoso da planta em pessoas reclusas em campos de concentração, a fim de esterilizálas; e que os escravos jamaicanos eram punidos pelos "senhores", tendo partes da planta esfregadas em suas bocas (Gardner, 1994).

Há controvérsias quanto ao tipo de intoxicação causada por D. picta. Alguns autores consideram que ocorre somente irritação mecânica devido à ação das ráfides, e outros que ocorre irritação mecânica seguida da penetração de agentes químicos presentes nas fendas $\mathrm{e}$ farpas das ráfides, capazes de provocar inflamação (Sakai et al., 1972).

Pelo fato de ser uma planta de cultivo doméstico, é essencial um estudo morfológico abrangente sobre a espécie, principalmente das partes da planta que ficam expostas. Apesar de muitos estudos químicos e ensaios clínicos terem sido realizados com a espécie, trabalhos comparativos de anatomia dos órgãos de $D$. picta não foram encontrados na literatura. Desta forma, este trabalho teve por objetivo analisar comparativamente a estrutura dos órgãos vegetativos aéreos e subterrâneos desta espécie, com ênfase na distribuição de cristais, laticíferos e grãos de amido nos tecidos, visto que tais estruturas participam do processo de toxicidade da planta (Gardner, 1994; Carneiro et al., 1985; Prychid; Rudall 1999; Judd et al., 2002; Oliveira et al., 2003).

\section{MATERIAL E MÉTODOS}

Pecíolos e regiões mediana e do bordo de folhas adultas e jovem (metade do comprimento da adulta), entrenós de caules aéreos e subterrâneos, e a região de absorção (contendo pêlos radiculares) de raízes foram coletados de dois indivíduos cultivados em Ribeirão Preto, SP, Brasil.

O material testemunho está armazenado no laboratório de Farmacobotânica da Faculdade de Ciências Farmacêuticas de Ribeirão Preto, Universidade de São Paulo.

Parte do material coletado foi mantida fresca para a realização de testes histoquímicos e a outra parte foi fixada em FAA 50 (Johansen, 1940) para a confecção de lâminas semi-permanentes e permanentes.

Lâminas semi-permanentes foram obtidas de cortes a mão livre corados com safrablau e montados em lâmina com gelatina glicerinada (Kraus; Arduin, 1997). Lâminas permanentes foram obtidas após desidratação do material em série etanólica, inclusão em parafina, utilizando o xilol como solvente, seccionamento em micrótomo rotativo (7 a $10 \mu \mathrm{m})$, reidratação, coloração com azul de toluidina 0,05\% (O'Brien et al., 1964), desidratação e montagem da lâmina em resina sintética

Tabela 1. Distribuição de cristais, laticíferos e grãos de amido nos órgãos vegetativos de Dieffenbachia picta Schott. O símbolo - indica ausência.

\begin{tabular}{|c|c|c|c|c|c|}
\hline \multirow{2}{*}{ órgãos } & & \multicolumn{2}{|c|}{ idioblastos cristalíferos } & \multirow{2}{*}{ laticífero } & \multirow{2}{*}{ grão de amido } \\
\hline & & ráfide & drusa & & \\
\hline \multirow{3}{*}{$\begin{array}{l}\text { folha } \\
\text { adulta }\end{array}$} & pecíolo & parênquima & parênquima & $\begin{array}{l}\text { colênquima, } \\
\text { aerênquima }\end{array}$ & - \\
\hline & nervura central & parênquima & parênquima & $\begin{array}{l}\text { colênquima, } \\
\text { parênquima }\end{array}$ & - \\
\hline & bordo & parênquima & $\begin{array}{l}\text { parênquima e } \\
\text { epiderme }\end{array}$ & - & - \\
\hline \multirow{3}{*}{$\begin{array}{l}\text { folha } \\
\text { jovem }\end{array}$} & pecíolo & parênquima & parênquima & - & - \\
\hline & nervura central & parênquima & parênquima & - & - \\
\hline & bordo & parênquima & $\begin{array}{l}\text { parênquima e } \\
\text { epiderme }\end{array}$ & - & - \\
\hline caule aéreo & entrenó & $\begin{array}{l}\text { parênquima e } \\
\text { colênquima }\end{array}$ & $\begin{array}{l}\text { parênquima e } \\
\text { colênquima }\end{array}$ & $\begin{array}{l}\text { colênquima, } \\
\text { parênquima }\end{array}$ & $\begin{array}{l}\text { parênquima próximo ao } \\
\text { feixe vascular }\end{array}$ \\
\hline rizoma & entrenó & parênquima & $\begin{array}{l}\text { parênquima e } \\
\text { colênquima }\end{array}$ & $\begin{array}{l}\text { colênquima, } \\
\text { parênquima }\end{array}$ & $\begin{array}{l}\text { clorênquima e } \\
\text { parênquima próximo ao } \\
\text { feixe vascular }\end{array}$ \\
\hline \multirow[t]{2}{*}{ raiz } & $\begin{array}{l}\text { região de } \\
\text { absorção }\end{array}$ & meristema & $\begin{array}{l}\text { parênquima e } \\
\text { meristema }\end{array}$ & - & $\begin{array}{l}\text { parênquima próximo ao } \\
\text { feixe vascular }\end{array}$ \\
\hline & & & & & $\begin{array}{r}\text { Rev. Bras. Farmacogn } \\
\text { Braz J. Pharmacogn } \\
\text { 16(Supl.):dez. } 2006\end{array}$ \\
\hline
\end{tabular}


Tabela 2. Análise comparativa da dissolução dos cristais por ácido clorídrico $10 \%$ em órgãos vegetativos de Dieffenbachia picta Schott. Os símbolos + indicam que houve dissolução dos cristais e - não houve dissolução.

\begin{tabular}{|c|c|c|c|c|}
\hline \multirow{2}{*}{ órgão } & & \multicolumn{3}{|c|}{ tempo (min) } \\
\hline & & 10 & 20 & 30 \\
\hline \multirow{6}{*}{ folha } & pecíolo de folha adulta & + & + & + \\
\hline & pecíolo de folha jovem & + & + & + \\
\hline & nervura central de folha adulta & - & + & + \\
\hline & nervura central de folha jovem & - & + & + \\
\hline & bordo de folha adulta & + & + & + \\
\hline & bordo de folha jovem & + & + & + \\
\hline caule & entrenó & - & - & + \\
\hline rizoma & entrenó & - & + & + \\
\hline raiz & região de absorção & + & + & + \\
\hline
\end{tabular}

(Gerlach, 1969).

Para a realização dos testes histoquímicos, parte dos cortes a mão livre do material fresco foi mantida sem coloração; a outra parte foi submetida aos seguintes reagentes para a confirmação da natureza dos cristais e das substâncias presentes nos laticíferos: ácido acético glacial para detecção de cristais de carbonato de cálcio; ácido clorídrico $10 \%$ para cristais de carbonato ou oxalato de cálcio; violeta cristal para cristais de sílica (Kraus; Arduin, 1997); Sudam III para lipídios (Johansen, 1940); lugol para grãos de amido (Johansen, 1940); anilina azul escura para proteínas (Fisher, 1968); reagente de Dragendorff para alcalóides (Svendsen; Verpoorte, 1983). Os testes com reagente de Dragendorff para alcalóides (Svendsen; Verpoorte, 1983) e Sudam III para lipídios (Johansen, 1940) foram realizados também para o látex.

O tempo de dissolução dos cristais foi comparado nos órgãos analisados. Os cortes foram retirados dos ácidos clorídrico e acético glacial $10 \mathrm{~min}, 20 \mathrm{~min}$ e 30 min após o início da reação.

Fotomicrografias foram obtidas em fotomicroscópio Leica DM 500 e as escalas nas mesmas condições ópticas.

\section{RESULTADOS}

\section{Estrutura anatômica}

A lâmina foliar da folha jovem e adulta é constituída por epiderme unisseriada (Figs. 1, 2), mesofilo dorsiventral constituído por uma camada de parênquima paliçádico e duas a três de parênquima lacunoso (Fig.1). A nervura central não é conspícua; apresenta epiderme unisseriada, duas a três camadas de colênquima subepidérmico, várias camadas de parênquima abaixo do colênquima e feixes vasculares colaterais dispersos no parênquima (Fig. 2). As nervuras secundárias são formadas por feixes vasculares colaterais. Os feixes vasculares da nervura central (Fig. 2) e das nervuras secundárias são delimitados por uma bainha parenquimática unisseriada. O pecíolo apresenta epiderme unisseriada (Fig. 3), colênquima subepidérmico angular com cinco a sete camadas de células (Fig. 3), e feixes vasculares colaterais dispersos no aerênquima (Figs. 4, 5).

Entrenós do caule aéreo (Figs. 6-9) e subterrâneo (Fig. 10) apresentam epiderme unisseriada (Fig. 7), colênquima subepidérmico, cujas células apresentam espessamento angular (Fig. 7), sendo sete a 10 camadas no caule aéreo (Figs. 6, 7) e seis a oito no subterrâneo (Fig. 10), e feixes vasculares colaterais (Figs. 8, 10) dispersos no parênquima amilífero (Figs. 9, 10), que ocupa todo a região central do órgão.

A raiz é adventícia, apresenta epiderme unisseriada, córtex parenquimático no qual a exoderme e a endoderme não são visualmente conspícuas, cilindro vascular constituído por xilema e floema primários, circundados por uma camada de células pericíclicas, e medula parenquimática (Fig. 11). Foram observadas raízes laterais originadas do periciclo, em frente aos pólos de xilema (Fig. 11).

\section{Cristais}

Células (idioblastos) contendo drusas e agrupamentos de ráfides foram encontradas na folha, no caule, no rizoma (caule subterrâneo) e na raiz (Tabela 1).

$\mathrm{Na}$ nervura central da folha adulta, idioblastos com ráfides (Fig. 2) e drusas concentram-se no colênquima da região abaxial. Na nervura central da folha jovem, idioblastos com ráfides se concentram em células no colênquima da região abaxial, e idioblastos com drusas ocorrem dispersos por todo o colênquima. $\mathrm{Na}$ região do bordo, idioblastos com ráfides e com drusas encontramse no mesofilo (Fig. 1), embora ocorram idioblastos com drusas na epiderme no bordo da folha adulta. No pecíolo da folha, tanto as ráfides (Fig. 4) como as drusas encontram-se em idioblastos no parênquima, porém aqueles com ráfides concentram-se na região abaxial e 

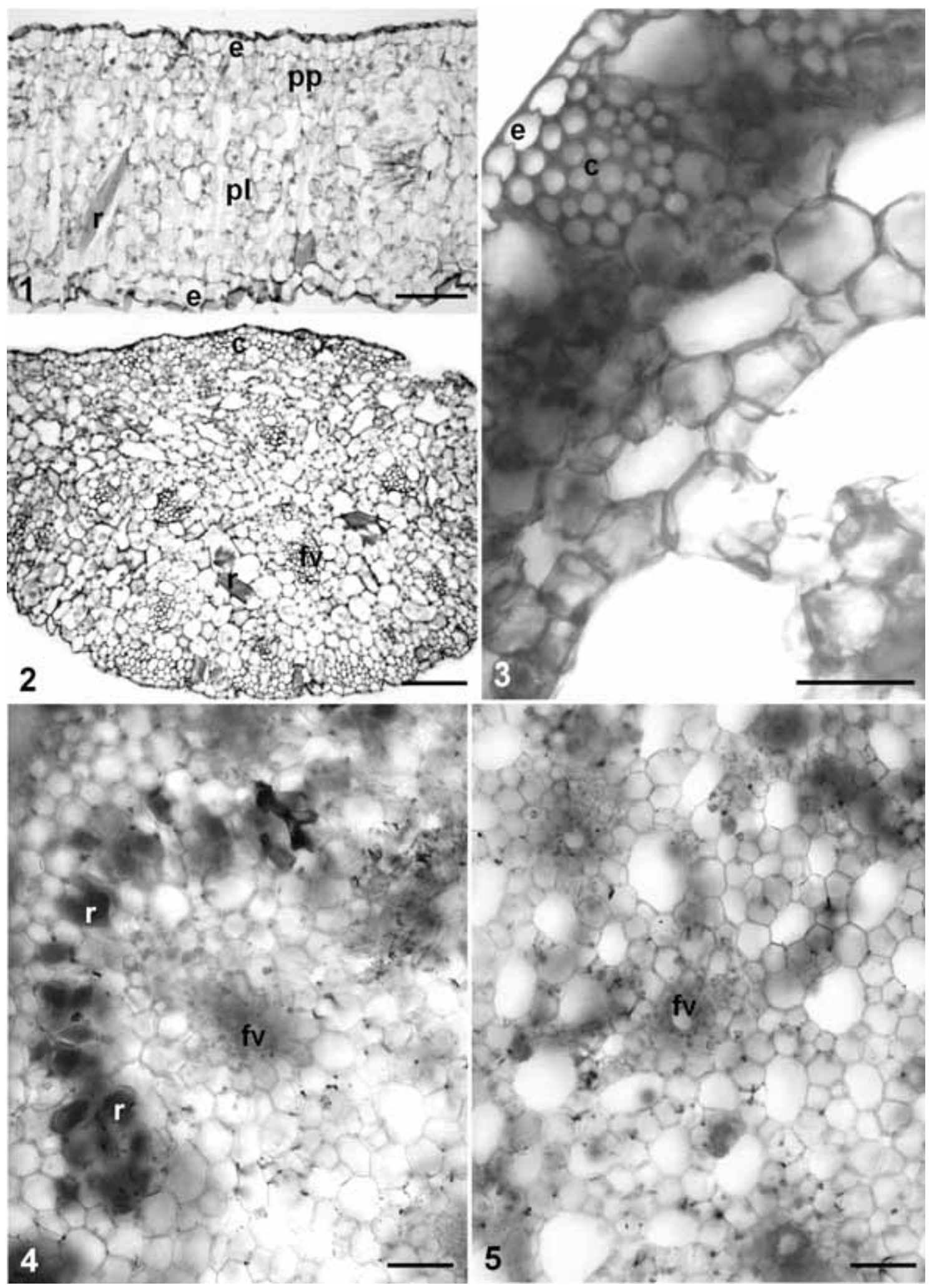

Figuras 1-5. Seções transversais da folha de Dieffenbachia picta Schott. 1. Lâmina foliar. Mesofilo constituído por parênquima paliçádico e lacunoso. 2. Nervura central da lâmina foliar com feixes vasculares dispersos. Observe os idioblastos contendo ráfides no mesofilo e no parênquima da nervura central. 3. Pecíolo. Epiderme unisseriada e colênquima subepidérmico. 4. Pecíolo. Feixes vasculares colaterais rodeados por idioblastos contendo ráfides. 5. Pecíolo. Feixes vasculares colaterais dispersos no aerênquima. Símbolos: $\mathrm{c}=$ colênquima, $\mathrm{e}=$ epiderme, $\mathrm{fv}=\mathrm{feixe}$ vascular, $\mathrm{pp}=$ parênquima paliçádico, $\mathrm{pl}=$ parênquima lacunoso, $\mathrm{r}=$ ráfides. Barras em 1, $2=83 \mu \mathrm{m}$; em $3=15 \mu \mathrm{m}$; em $4,5=30 \mu \mathrm{m}$. 


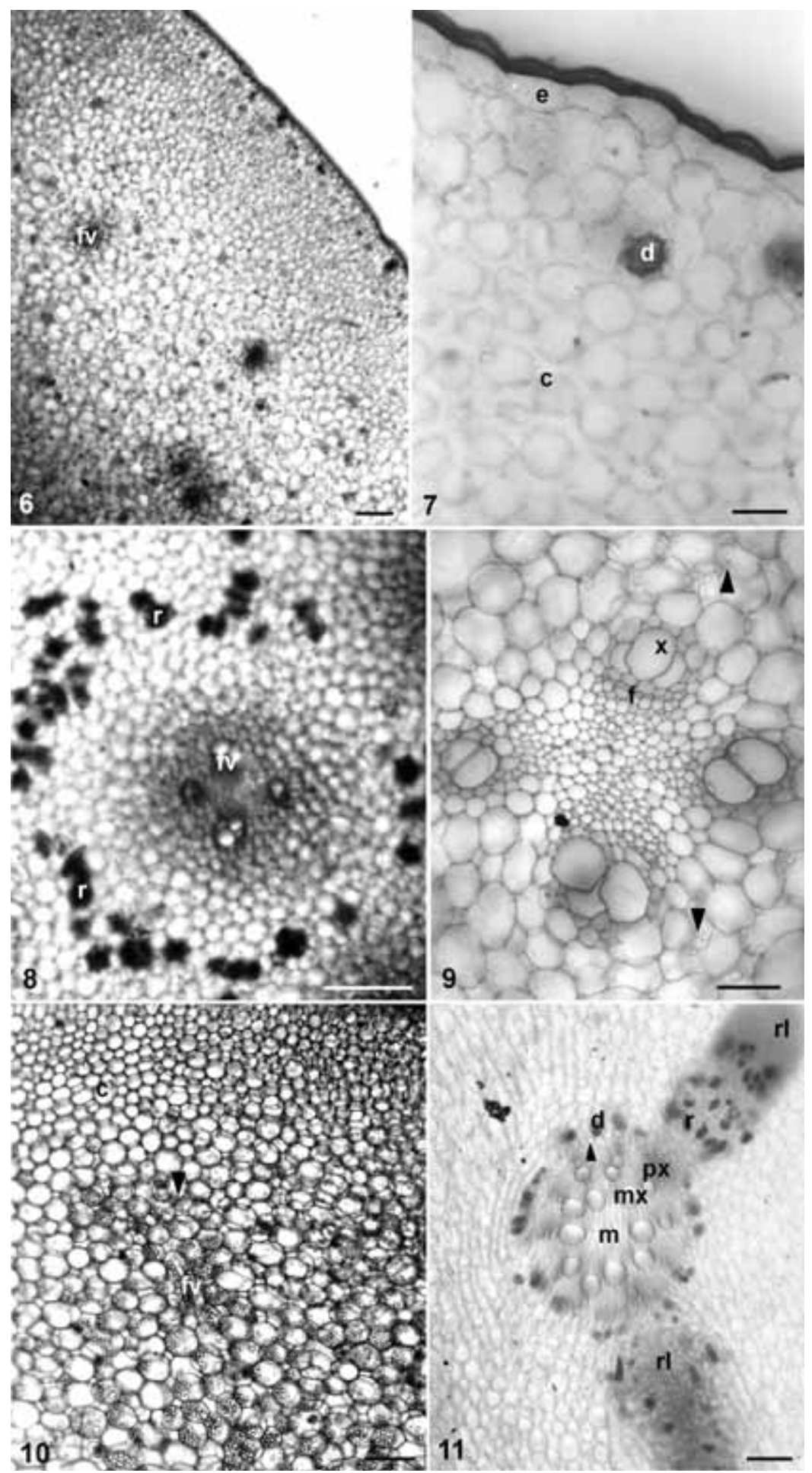

Figura 6-11. Seções transversais do caule e da raiz adventícia de Dieffenbachia picta Schott. 6-9. Caule aéreo. 6. Epiderme unisseriada, colênquima subepidérmico e feixes vasculares dispersos no parênquima. 7. Detalhe da epiderme, de um idioblasto contendo drusa e do colênquima angular. 8. Feixes vasculares centrais rodeados por idioblastos contendo ráfides. 9. Detalhe dos feixes vasculares colaterais dispersos no parênquima amilífero (setas). 10. Caule subterrâneo. Colênquima supepidérmico e feixes vasculares dispersos no parênquima amilífero (seta). 11. Raiz adventícia. Córtex parenquimático, endoderme unisseriada (seta) e cilindro vascular delimitado por idioblastos contendo drusas. Observe a saída das raízes laterais do periciclo e os idioblastos contendo ráfides dispersos nos tecidos meristemáticos. Símbolos: $\mathrm{c}=$ colênquima, $\mathrm{d}=$ drusa, $\mathrm{e}=$ epiderme, $\mathrm{f}=$ floema, $\mathrm{fv}=$ feixe vascular, $\mathrm{m}=\mathrm{medula}, \mathrm{mx}$ $=$ metaxilema, $\mathrm{px}=$ protoxilema, $\mathrm{r}=$ ráfides, $\mathrm{rl}=$ raiz lateral, $\mathrm{x}=$ xilema. Barras em $6,10,11=80 \mu \mathrm{m} ; \mathrm{em} 7,9=26$ $\mu \mathrm{m}$; em $8=150 \mu \mathrm{m}$. 
com drusas por todo este tecido.

No caule aéreo, idioblastos com drusas localizam-se no colênquima e nas camadas mais externas do parênquima (Figs. 6, 7). Idioblastos com ráfides localizam-se no colênquima e no parênquima que circunda os feixes vasculares (Fig. 8).

No caule subterrâneo (rizoma), idioblastos com drusas ocorrem dispersos no parênquima cortical e no colênquima subepidérmico. Já os idioblastos com ráfides circundam irregularmente o cilindro central. $\mathrm{Na}$ raiz, idioblastos com drusas ocorrem nos tecidos meristemáticos subapicais e nas camadas próximas à endoderme (Fig. 11), enquanto idioblastos com ráfides ocorrem apenas nos tecidos meristemáticos subapicais (Fig. 11).

Os testes confirmaram que a composição química dos cristais é de oxalato de cálcio. Não houve diferença no tempo de dissolução dos cristais comparando-se as folhas jovens às adultas. Comparando-se as folhas ao caule aéreo observou-se que neste a dissolução dos cristais ocorreu após um tempo maior; a dissolução dos cristais ocorreu mais rapidamente na raiz que no rizoma (Tabela 2). O conteúdo dos idioblastos cristalíferos apresentou reações positivas para lipídios e proteínas. $\mathrm{Na}$ folha e no caule aéreo também foram registrados alcalóides nos idioblastos cristalíferos (reação positiva para o Reagente de Dragendorff).

\section{Grãos de amido}

Grãos de amido (Tabela 1) ocorrem na forma de bastonetes no caule aéreo (Fig. 9) e nas formas esférica e em bastonetes no rizoma (Fig. 10). No caule aéreo, estão presentes nas células parenquimáticas corticais próximas aos feixes vasculares (Fig. 9) e ao colênquima. No rizoma, ocorrem apenas no parênquima cortical próximo à região vascular (Fig. 10). Os grãos de amido apresentaram reação positiva também para anilina azul escura, o que sugere que também apresentam natureza protéica.

\section{Laticíferos}

Laticíferos ocorrem ao redor dos feixes vasculares e entremeando o colênquima da nervura central da lâmina foliar, do pecíolo e do caule aéreo e subterrâneo (Tabela 1). Testes com Reagente de Dragendorff e Sudam III confirmaram a presença de alcalóides e lipídios no látex. Ráfides foram observadas dispersas no interior dos laticíferos.

\section{DISCUSSÃO}

Dentre os três tipos de cristais relatados para 14 espécies de Araceae - drusas, ráfides e areia cristalífera (Genua; Hillson, 1985), drusas e ráfides foram observados em Dieffenbachia picta neste trabalho e em D. maculata por Genua e Hillson (1985). A distribuição de drusas e ráfides na folha de Dieffenbachia apresenta valor diagnóstico para as espécies. A presença de drusas e a ausência de ráfides na epiderme foliar de $D$. picta, por exemplo, diferem-na de $D$. maculata, pois esta última apresenta drusas apenas no mesofilo e ráfides no mesofilo e na epiderme foliar (Genua; Hillson, 1985).

Se considerarmos que a presença de cristais de oxalato de cálcio é um indicativo de toxicidade, este trabalho corrobora a afirmação de Gardner (1994) de que D. picta é uma espécie vegetal tóxica, causadora de inflamação, pois cristais de oxalato de cálcio na forma de ráfides e drusas foram observados em grandes quantidades em todos os órgãos vegetativos da planta (folha, caule aéreo e subterrâneo, e raiz). A irritação química citada por Gardner (1994) provavelmente está relacionada à associação dos cristais a substâncias tóxicas, como alguns lipídios, proteínas e alcalóides, encontrados nos idioblastos cristalíferos. Além disso, também foi confirmada a presença de alcalóides no látex da planta. Num estudo com Xanthosoma sagittifolium, espécie também pertencente à família Araceae, observou-se que as ráfides apresentavam sulcos e fendas que permitiam a entrada de substâncias irritantes, junto com os cristais, na mucosa da boca e da garganta de quem a ingerisse (Sakai et al., 1972).

Apesar das controvérsias referentes à relação entre a presença de cristais e a toxicidade dos órgãos das plantas tóxicas (Carneiro et al., 1985; Rauber, 1985; Doaigey, 1991; Gardner, 1994; Chiou et al., 1997), prevenimos que o caule de D. picta apresenta maior quantidade de cristais que a folha, o que pode ser comprovado pelo maior tempo de dissolução dos cristais presentes no caule. A maioria dos trabalhos (Rauber, 1985; Genua; Hillson, 1985; Gardner, 1994) trata de levantamentos de cristais em folhas e os problemas acarretados por eles por contato ou ingestão deste órgão, em especial quanto à presença de drusas, que tem sido o principal cristal associado à irritação mecânica nas aráceas (Genua; Hillson, 1985). Pouca atenção tem sido dada ao caule aéreo e ao rizoma, apesar de haver relatos de lesão da córnea por contato com ramos de D. picta (Chiou et al., 1997).

Comparando-se os órgãos aéreos aos subterrâneos de D. picta nota-se que os cristais e laticíferos concentram-se na parte aérea, sendo que os cristais foram mais observados no caule e os laticíferos na folha. A distribuição dos cristais, laticíferos e amido é muito semelhante entre caule aéreo e rizoma; entretanto, a forma do grão de amido varia, sendo que o caule apresenta grãos na forma de bastonete e o rizoma nas formas esférica e bastonete. A variação da morfologia dos grãos de amido entre caule e rizoma é intrigante, uma vez que sua distribuição tecidual é muito semelhante nos dois órgãos. Contudo, sua ocorrência, próximo aos feixes vasculares, às células contendo cristais e aos laticíferos, evidencia sua função de armazenamento e produção de energia para a planta, visto que os tecidos constituintes 
dos feixes vasculares e os laticíferos são responsáveis pelo trânsito de substâncias pela planta, o que requer um alto consumo de energia, e que a produção de cristais também é um processo celular com gasto energético (Fahn, 1979).

Cristais e laticíferos apresentaram distribuição diferente, ou seja, não são encontrados associados. Mesmo assim, não é possível afirmar que não haja uma combinação de látex e cristais no efeito tóxico produzido pela planta, ou que cada um haja sozinho com suas substâncias associadas resultando em um mesmo efeito (Rauber, 1985).

Devido ao fato de ocorrerem vários casos de intoxicação com $D$. picta (Oliveira, 2002) e pelo fato de ela ser uma planta ornamental cultivada em muitas residências, é necessário um cuidado especial com crianças que são atraídas pelas folhas chamativas da planta e com animais que podem se intoxicar ingerindo partes da mesma.

Este estudo descreveu detalhadamente a anatomia dos órgãos vegetativos de $D$. picta, e pode auxiliar na profilaxia da intoxicação por ingestão, uma vez que os principais tecidos onde se distribuem os cristais e os laticíferos foram evidenciados.

\section{REFERÊNCIAS}

Carneiro CMTS, Neves LJ, Pereira NA 1985. Mecanismo tóxico de comigo-ninguém-pode, Dieffenbachia picta Schott (Araceae). An Acad Bras Cienc 57: 392-393.

Chiou AG-Y, Cadez R, Bohnke M 1997. Diagnosis of Dieffenbachia induced corneal injury by confocal microscopy. Brit J Ophtalmol 81: 168-169.

Doaigey AR 1991. Occurrence, type, and location of calcium oxalate crystals in leaves and stems of 16 species of poisonous plants. Am J Bot 78: 1608-1616.

Fahn A 1979. Secretory Tissues in Plants. London: Academic Press Inc.

Fisher DB 1968. Protein staining of ribboned epon sections for light microscopy. Histochemie 16: 92-96.

Gardner DG 1994. Injury to the oral mucous membranes caused by the common houseplant, dieffenbachia. A review. Oral Surgery Oral Medicine Oral Pathology 78: 631633.

Genua JM, Hillson CJ 1985. The occurrence, type and location of calcium oxalate crystals in the leaves of fourteen species of Araceae. Ann Bot 56: 351-361.

Gerlach D 1969. Botanische Mikrotechnik. Stuttgart: Georg. Thieme Verlag.

Johansen DA 1940. Plant Microtechnique. New York: McGrawHill Book Company Inc.

Joly AB 1991. Botânica - Introdução à Taxonomia Vegetal. $10^{\mathrm{a}}$ ed. São Paulo: Companhia Editora Nacional.

Judd WS, Campbell CS, Kellogg EA, Stevens PF. 2002. Plant Systematics - A Phylogenetic Approach. Sunderland: Sinauer associates, Inc.

Kraus JE, Arduin M 1997. Manual Básico de Métodos em Morfologia Vegetal. Seropédica: Edur.

O'Brien TP, Feder N, McCully ME 1964. Polychromatic staining of plant cell walls by toluidine blue $\mathrm{O}$.
Protoplasma 59: 368-373.

Oliveira RB 2002. Plantas tóxicas em Ribeirão Preto: conhecer para prevenir acidentes. Monografia de conclusão de curso. 100p. Faculdade de Filosofia Ciências e Letras de Ribeirão Preto, Universidade de São Paulo.

Oliveira RB, Godoy SAP, Costa FB 2003. Plantas Tóxicas: Conhecimento e Prevenção de Acidentes. Ribeirão Preto: Holos.

Prychid CJ, Rudall PJ 1999. Calcium oxalate crystals in Monocotyledons: A review of their structures and systematics. Ann Bot 84: 725-739.

Rauber A 1985. Observations on the idioblasts of Dieffenbachia. Clin Toxicol 23: 79-90.

Sakai WS, Hanson M, Jones CR 1972. Raphides with barbs and grooves in Xanthosoma sagittifolium (Araceae). Science 178: 314-315.

Schutz A 1968. Introdução ao Estudo da Botânica Sistemática, vol. II $3^{\text {a }}$ ed. Rio de Janeiro: Ed. Globo.

Souza VC, Lorenzi H 2005. Botânica Sistemática. Guia ilustrado para identificação das famílias de Angiospermas da flora brasileira, baseado em APG II. Nova odessa: Instituto Plantarum de Estudos da Flora Ltda.

Svendsen AB, Verpoorte R 1983. Cromatography of Alkaloids. New York: Elsevier Scientific Publishing Company.

Tokarnia CN, Döberreiner J, Peixoto PV 2000. Plantas Tóxicas do Brasil. Rio de Janeiro: Editora Helianthus. 